\title{
A COMPARISON OF THE CITY LIFE QUALITY INDEX FOR EUROPEAN CITIES USING THE WASPAS AND VIKOR METHODS
}

DOI: 10.17261/Pressacademia.2020.1217

JBEF- V.9-ISS.2-2020(4)-p.97-117

Hakan Altin

Aksaray University, Faculty of Economics and Administrative Sciences, Department of Business, Aksaray, Turkey. hakanaltin@aksaray.edu.tr, ORCID: 0000-0002-0012-0016

Date Received: April 10, 2020

Date Accepted: June 9, 2020

To cite this document

Altın, H., (2020). A comparison of the city life quality index for European cities using the Waspas and Vikor methods. Journal of Business, Economics and Finance (JBEF), V.9(2), p.97-117.

Permanent link to this document: $\mathrm{http}: / /$ doi.org/10.17261/Pressacademia.2020.1217

Copyright: Published by PressAcademia and limited licensed re-use rights only.

\section{ABSTRACT}

Purpose- The main purpose of this study was to compare the results of the city life quality index using the WASPAS and VIKOR methods, two of the multi-criteria decision-making methods.

Methodology- For this, in the first stage, a decision matrix was created. In the second stage, the ranking results obtained from WASPAS and VIKOR methods were compared with each other. In the final stage, the results obtained from the methods were compared with the results of the life quality index ranking.

Findings- When the findings were examined, there was a strong positive relationship between the methods used and the values obtained. Accordingly, there was a positive relationship between the WASPAS and VIKOR methods, demonstrating that the two methods can be used interchangeably. The same strong relationship was also valid for the life quality index.

Conclusion- Accordingly, the life quality index calculations and the WASPAS and VIKOR calculations provided very similar results. The results were found to be statistically significant.

Keywords: Multicriteria decision-making (MCDM), WASPAS, VIKOR, lambda, sensitivity analysis.

JEL Codes: C00, C02, G11

\section{INTRODUCTION}

Multi-criteria decision-making (MCDM) methods and their success in evaluating different alternatives in terms of various criteria for the possible selection of the optimal alternative have become increasingly important in analyzing and solving complex problems based on real life. MCDM methods eliminate measurement problems such as the existence of different measurement units and different alternatives between the criteria under the presence of more than one immeasurable and contradictory criteria. MCDM methods primarily aim to evaluate and rank the available alternatives. In this way, decision making problems can be solved with various MCDM methods.

Decision-making is an inherent process, whether complex or simple. Many of the complex real-life problems involve conflicting and multi-criteria processes. Procedures for determining the optimal solution for an MCDM problem include calculating the benefits of alternatives and listing these benefits. The solution alternative with the greatest benefit is considered the most suitable solution. Due to the complex nature of the problem and the contradictory nature of the criteria, a solution for a problem that provides a compromise helps the decision maker reach a final decision. An MCDM problem is expressed using a decision matrix.

The main purpose of the study is to compare the results of the city life quality index using the WASPAS and VIKOR methods, two of the multi-criteria decision-making methods. For this purpose, in the first stage, a decision matrix was created. In the second 
stage, the ranking results obtained from WASPAS and VIKOR methods were compared with each other. In the final stage, the results obtained from the methods were compared with the results of the life quality index ranking.

\section{LITERATURE}

The literature review consists of two parts. First, the Waspas Method. The second is the Vikor method.

\subsection{The WASPAS Method}

Chakraborty and Zavadskas (2014) examined decision-making problem in the manufacturing process. To survive in today's global competitive environment, it is now imperative for manufacturing organizations to make quick and accurate decisions regarding the efficient use of scarce resources. There are several multi-criteria decision-making (MCDM) methods to help these organizations choose the optimal path for decisive action. The Weighted Aggregated Sum Product Assessment or the WASPAS method was used as an effective MCDM tool in the study. It is observed that this method has the capacity to rank alternatives correctly in all the selection issues considered. In addition, the effect of the lambda $(\lambda)$ parameter on the ranking performance of the WASPAS method was examined for the effectiveness of the method and the accuracy of the ranking. Accordingly, they found that a better performance was obtained at higher lambda values.

Zavadskas et al. (2014) evaluated the WASPAS method in his study. Different methods were proposed within the framework of the utility theory for multi-criteria decision-making. Among the proposed methods, the weighted sum and the weighted product models (WSM and WPM) are well known and widely used. The WASPAS method has been proposed to increase the accuracy of the WSM and the WPM. In the proposed WASPAS-IVIF method, they expressed uncertainty about determining the evaluations of decision-makers regarding alternative performance according to the importance of the criteria and/or criteria with intuitionistic fuzzy interval numbers. Thus, they combined the strength of IVIF in handling uncertainty with the improved accuracy of WASPAS, making it a method that can be used in real-world applications.

Madić et al. (2014) discussed the process of machining in manufacturing. Choosing the most suitable machining process for a specific machining application is difficult, requiring consideration of a number of technological and economic criteria. Therefore, the process is considered a multi-criteria decision-making (MCDM) method. Using the recently developed WASPAS method, the study focused on a multi-criteria economic analysis of various machining processes. A binary comparison matrix was applied to determine the relative importance of the criteria considered. In addition, the effect of the $\lambda$ parameter on the ranking performance of the WASPAS method was examined for the effectiveness of the method and the accuracy of the ranking. The choice of a specific machining process is a crucial task in the manufacturing environment, and this task can be accomplished with the WASPAS method.

In their study, Chakraborty et al. (2015) investigated the applicability and usefulness of the WASPAS method as a decision-making tool in five cases, finding that the rankings obtained with the WASPAS method closely match those obtained by past researchers for all problems. The most appropriate $\lambda$ values were calculated for each problem evaluated. Then, the ranking performance of the WASPAS method was examined according to the changing $\lambda$ values. The accuracy of the WASPAS method, which will help its widespread application as an effective MCDM tool, was proven. Since the WASPAS method is, by its nature, based on simple and powerful mathematics, it can be successfully applied to any decision-making problem.

Zavadskas et al. (2015a) attempted to verify the applicability and effectiveness of the WASPAS method in solving five nontraditional machining (NTM) selection problems. They found that the WASPAS method was able to optimally solve both single response and multi-response optimization problems of NTM operations. The main advantage of the WASPAS method is that it can define the optimal parametric combination of the NTM process. Determining the optimal values of $\lambda$ further increases the accuracy and effectiveness of this method in the decision-making process. It was proven that WASPAS can be used as a simple and robust optimization tool.

Zavadskas et al. (2015b) conducted environmental sustainability assessment in their study. In recent years, sustainability principles have gained importance in all areas of life. Since the household and construction wastes of manufactured products cannot be easily removed, they are one of the biggest problems for urban areas. This issue has increased the demand for system technologies for the life cycle of wastes and the development of proper disposal methods. The construction of a waste incinerator is a complex process that includes all factors of the principles of sustainability. Multi-criteria decision-making methods (MCDM) offer powerful and flexible techniques for solving many sustainability problems. In the study, WASPAS-SVNS, a new extension of the WASPAS 
method, was proposed, a method that can solve the location problem for waste incineration plants due to the requirements of sustainability factors.

Ghorabaee, et al. (2016) examined the environmental performance of suppliers which. affects the overall environmental performance of the supply chain. Therefore, the selection of green suppliers is a strategic decision-making problem for gaining a competitive edge. The green supplier selection problem is often considered an MCDM issue. In this study, an extended WASPAS method for the solution of the problem was proposed. In the proposed approach, some changes were made in the classical normalization and WPM measurement process, and the results demonstrated that the proposed approach had good efficiency and stability.

Karabašević et al. (2016) examined the topic of personnel selection. Human resources management generally involves different activities that have an impact on improving the efficiency and effectiveness of the employees' performance and work and in directing employees to achieve company goals. Finding and employing qualified personnel is especially important in ensuring the adequate human potential of the management of human resources. They suggested that the proposed SWARA-WASPAS approaches were adaptable, applicable, and easy to use for personnel selection. Furthermore, with some modifications, the SWARA-WASPAS approach could be used in other areas.

Urosevic et al. (2017) examined the issue of personnel selection in the tourism industry based on the SWARA and WASPAS methods. Tourism is one of the leading economic sectors in the world and represents a major source of employment, and employees are one of the industry's most important strategic resources. In today's business conditions, the highest level of competence has become an important factor in an organization achieving success and competitiveness in the market. From the numerical example used, it could be concluded that the proposed SWARA WASPAS approaches were adaptable and easily applicable and could be used to solve problems of personnel selection. In addition, the proposed approach could be used to solve problems in other areas.

Keshavarz et al. (2017) examined the evaluation of third-party logistics (3PL) providers, an important issue for businesses that try to reduce their capital expenditure and logistics costs as well as to improve operational efficiency and customer service. In the study evaluating a suitable 3PL provider, a new integrated approach based on CRITIC and WASPAS method was proposed, and the results proved the reliability and effectiveness of the ranking results.

In their study, Stanujkić, and Karabašević (2018) proposed a new method based on the use of intuited fuzzy numbers to ensure that the WASPAS method could be used to solve many more decision-making problems. The effectiveness and usability of the proposed approach were discussed using the example of a website assessment. Websites play a crucial role in modern companies. Based on the numerical example used in the study, the WASPAS method proved to be highly effective and feasible for website assessment.

Deveci, et al. (2018) proposed a WASPAS- and TOPSIS-based method for the selection of a car sharing station. Car sharing is an important element of the increasingly common sharing economy in the world. For this reason, companies operating in the industry want to increase their capacity and market share by adding new vehicle sharing stations. The proposed method involved a case study that determined the best location for a new car-sharing station among four alternatives, and the method was reported to be a more accurate decision-making tool for problems with a high level of uncertainty.

Stojić et al. (2018) examined the issue of supplier selection. The decision-making process requires certain factors to be pre-defined and implemented, especially when it comes to complex areas such as supply chain management. The most important issue that determines the subsequent flow of the supply chain is choosing the most suitable supplier. In the study, the relative values of the weight coefficients of the criteria were calculated using the AHP method. Then, the evaluation and ranking of the suppliers were carried out using the WASPAS method. The results were compared with different multi-criteria decision-making methods. The proposed model allowed the evaluation of alternatives despite the lack of quantitative or precise information in the information management process

\subsection{VIKOR}

Opricovic and Tzeng (2004) conducted a comparative analysis of VIKOR and TOPSIS in their study. The MCDM methods of VIKOR and TOPSIS are both based on an aggregate function that represents proximity to ideal. The VIKOR method presents the ranking index based on the measure of proximity to the ideal solution. The TOPSIS method uses two reference points but does not take 
into account the relative importance of distances from these points. While the VIKOR method uses linear normalization, the TOPSIS method uses vector normalization. The normalized value in the VIKOR method does not depend on the evaluation unit of a criterion function. Comparative analysis showed that these two methods used different normalizations and offered different aggregate functions for ranking.

Tong et al. (2007) investigated the optimization of multiple response processes in their study. Taguchi Methods, mostly used in engineering, are experimental methods used in industry to increase quality. These methods were developed to optimize singlereaction processes. In many cases, multiple responses need to be optimized simultaneously because some product designs, especially in the integrated circuit industry, are becoming increasingly complex to meet customers' demands. Although several procedures have been developed in recent years to optimize multiple response processes, the quality measurement indices do not take into consideration the differences in losses in the relative quality of the multiple responses. When multiple responses are considered, engineers often optimize based on their subjective experience. In this study, a systematic procedure was developed to apply VIKOR, a MCDM compromise ranking method, to optimize the multiple response process. The method can be used in multiple response processes.

Datta et al. (2010) used the concept of utility and the VIKOR method for supplier selection in their study. The results were compared with the gray relation technique. The results of the techniques used were very compatible with each other. The estimated supplier selection of the gray relation theory exactly matched the forecast of the VIKOR method. However, the result of the concept of utility was slightly different from the results of other techniques. However, all techniques provided reliable information for choosing the optimal outcome. The study displays the effectiveness of these MCDM techniques in solving such a vendor selection problem.

Devi (2011) used an expanded VIKOR method to solve a robot-selection problem. Decision making is the process of finding the optimal option among feasible alternatives. In classical multi-criteria decision-making methods, the ratings and weights of the criteria are fully known. VIKOR is a useful method for MCDM problems, especially when the decision maker cannot express or know his/her preferences at the beginning of the system design. The resulting compromise solution is acceptable to decision makers because compromise provides maximum group utility and minimum individual regret levels. The compromise solution here was a viable solution closest to the ideal solution, compromise referring to an agreement created with mutual privileges.

Bazzazi, et al. (2011) applied the modified VIKOR method in his study. In a highly qualified decision-making problem, a decision maker needs to choose the optimal alternative that meets the evaluation criteria among a range of solutions. It is often difficult to find an alternative that meets all the criteria at the same time, so a good compromise solution is preferred. The VIKOR method was developed for multi-criteria optimization of complex systems. This method focuses on ranking and selecting a number of alternatives in the presence of conflicting criteria. It offers a multi-criterion ranking index based on the measure of proximity to the ideal solution. The study provided an assessment model based on deterministic data to deal with the subjective perceptions of people in their decision processes and the uncertainty in their experiences.

Liu and Wu (2012) examined the competency assessment process of human resources with the VIKOR method. While the importance levels of the criteria were determined by the entropy method, they evaluated the issues of the ideal solution and the negative ideal solution produced by VIKOR. For the purpose of the assessment, they calculated a ratio value for each evaluation object and then listed them. They demonstrated the evaluation procedures and validity of the model. In addition, they developed different evaluation index systems for different personnel for positions such as production personnel, technical personnel, and management personnel.

Ju and Wang (2013) proposed a new method based on the traditional VIKOR method idea to solve multi-criteria group decisionmaking problems. Due to time pressure, lack of information or data, and the limited expertise of decision makers in the problem area, the criteria values and weights given by decision makers often vary. The method has the feature of preventing data corruption and loss that had previously occurred in information processing. It has a feature that can be used to solve engineering and management problems, and to make the optimal decision in all other areas, and a compromise solution can also be obtained. The VIKOR method is simple and easy to perform.

Rezaie et al. (2014) examined the performance of companies operating in the cement industry. In today's competitive environment, a firm's performance assessment and comparison with other companies provide important information to all stakeholders and companies so as to achieve their investment goals. In the study, an approach based on FAHP and VIKOR methods 
was presented. In its initial phase, the FAHP method was used to determine the weight of the criteria that directed the subjective decisions by the decision makers. Then, the VIKOR method was used to rank companies, a method that can evaluate the operation of a company and detect its competitiveness and weakness.

Opricovic, (2016) conducted a comparative analysis of the DEA-CCR model and the VIKOR method. The DEA model helps to determine the weights needed to maximize the efficiency of decision-making units. The basis of the DEA model is the evaluation of alternative decision-making units in terms of their efficiency in converting inputs into outputs. The multi-criteria decisionmaking method VIKOR uses a common set of weights that express the decision maker's preferences. In contrast, the CCA model of DEA does not do that. The weights used in the VIKOR method do not have an evident economic significance, but their use provides an opportunity to model real aspects of decision making, such as the structure of choice. When DEA and VIKOR were compared, it was observed that DEA was similar to VIKOR, but the results were different.

Zhang and Xing (2017) used the probabilistic VIKOR method to evaluate green supply chain initiatives in their study. To achieve sustainable economic and environmental protection goals, more and more companies are planning to implement green supply chain (GSC) initiatives in their products. Adoption of GSC initiatives also affects the operational performance of companies. Therefore, firms must carefully evaluate their performance when implementing GSC initiatives. To make such an assessment, they have developed a new probabilistic VIKOR approach in which various probabilistic values such as a probabilistic group utility measurement, a probabilistic individual regret measurement, and a probabilistic compromise measurement are calculated. The applied method provides a compromise solution based on these three measures.

\section{RESEARCH OBJECTIVE AND SCOPE}

The main purpose of this study was to compare the results of the city life quality index with the WASPAS and VIKOR methods. The quality of life index, in which a high score is desirable, is an estimate of the overall quality of life that takes into account the issues of the purchasing power index, in which a high score is desirable, the pollution index (low is desirable), the property price to income ratio (low is desirable), the cost of living index (low is desirable), the safety index (high is desirable), the health care index (high is desirable), the traffic commute time index (low is desirable), and the climate index (high is desirable). The WASPAS and VIKOR methods were used to determine the optimal solution for multi-criteria decision-making problems. The CRITIC and ENTROPY methods were used as objective weighting techniques in determining the importance of the criteria. These two techniques provided remarkably similar results to each other. In addition, weights did not have an evident significance, and the benchmark values and the weights were often varied. Therefore, the significance degrees (weights) of the criteria were calculated as $16.67 \%$.

A decision matrix was created in the first stage of the multi-criteria decision-making methods. The $86 \times 6$ decision matrix consists of 86 alternatives and six criteria. The criteria in the objective function were designated as $\mathrm{C} 1$, purchasing power index (max); $\mathrm{C} 2$, safety index (max); C3, health care index (max); C4, cost of living index (min); C5, traffic commute time index (min); and C6, pollution index $(\mathrm{min})$. The data used in this study were gathered from the Numbeo website.

\section{DATA AND METHODOLOGY}

Mathematical forms are given for the methods used in this section.

\subsection{Weighted Aggregated Sum Product Assessment Product Method (WASPAS)}

Chakraborty et al. (2015, pp.3-5) and Zavadskas et al. (2015, pp.78-79) were utilized for the mathematical form of the model.

The WASPAS method is a combination of the two well-known multi-criteria decision-making methods, the weighted sum model (WSM) and the weighted product model (WPM). Its implementation first begins with the development of a decision (evaluation) matrix.

$$
X=\left[x_{i j}\right]_{m \times n}
$$

Here, $x \mathrm{ij}$ is the performance of the alternative $\mathrm{i}$ according to the criterion $\mathrm{j}$. M indicates the number of alternatives, and $\mathrm{n}$ indicates the number of criteria. To make performance measurements comparable and dimensionless, all elements in the decision matrix were normalized using the following two equations: 
$\bar{x}_{i j}=\frac{x_{i j}}{\max _{i} x_{i j}}$ for beneficial criteria

$\bar{x}_{i j}=\frac{\min _{i} x_{i j}}{x_{i j}}$ for non-beneficial criteria,

Here, the overlined xij is the normalized value of xij.

In the WASPAS method, a common optimism criterion is sought based on the dual optimality criteria. The first criterion of optima, that is, a weighted average success criterion, is similar to the WSM method. It is a multi-criteria decision-making (MCDM) approach applied to evaluate a range of alternatives based on a range of decision criteria. According to the WSM method, the total relative importance of the first alternative is calculated as follows:

$Q_{i}^{(1)}=\sum_{j=1}^{n} \bar{x}_{i j} w_{j}$

$\mathrm{wj}$, is the (relative importance) weight of the criterion $\mathbf{j}$.

The total relative importance of the second alternative according to the WPM method is calculated using the following equation:

$\left.Q_{i}^{(2)}=\prod_{j=1}^{n} \overline{\left(x_{i j}\right.}\right)^{w j}$

Then, the following equation is recommended for a common general criterion of the weighted aggregate of additive and multiplicative methods.

$Q_{i}=0,5 Q_{i}^{(1)}+0,5 Q_{i}^{(2)}=0,5 \sum_{j=1}^{n} \bar{x}_{i j} w_{j}+0,5 \prod_{j=1}^{n} \overline{\left(x_{i j}\right)^{w j}}$

In the WASPAS method, to increase the ranking accuracy and effectiveness of the decision-making process, a more general equation is given to determine the total relative importance of the alternative as follows:

$\left.Q_{i}=\lambda Q_{i}^{(1)}+(1-\lambda) Q_{i}^{(2)}=\lambda \sum_{j=1}^{n} \bar{x}_{i j} w_{j}+(1-\lambda) \prod_{j=1}^{n} \overline{\left(x_{i j}\right.}\right)^{w j}, \lambda=0,0.1, \ldots, 1$

Applicable alternatives are now ranked according the $Q$ values, and the best alternative has the highest $Q$ value. Equation 6 becomes the WSM method when the $\lambda$ value is 0 while the WASPAS method converts to WPM and $\lambda$ is 1 . It was applied to solve MCDM problems with increased ranking accuracy, having the ability to achieve the highest prediction accuracy.

For a particular decision-making problem, the following formula was used to determine the optimal values of $\lambda$ when searching for the most extreme function.

$\lambda=\frac{\sigma^{2}\left(Q_{i}^{(2)}\right)}{\sigma^{2}\left(Q_{i}^{(1)}\right)+\sigma^{2}\left(Q_{i}^{(2)}\right)}$

Variances can be estimated by using the equations below: 


$$
\begin{aligned}
\sigma^{2}\left(Q_{i}^{(1)}\right) & =\sum_{j=1}^{n} w_{j}^{2} \sigma^{2}\left(\overline{x_{i j}}\right) \\
\sigma^{2}\left(Q_{i}^{(2)}\right) & =\sum_{j=1}^{n}\left[\frac{\prod_{j=1}^{n} \overline{\left(x_{i j}\right)^{w j}} w_{j}}{\left.\left.\overline{\left(x_{i j}\right.}\right)^{w j} \overline{\left(x_{i j}\right.}\right)^{(1-w j)}}\right] \sigma^{2}\left(\overline{x_{i j}}\right)
\end{aligned}
$$

Variance estimations of the normalized first criterion values are calculated as follows:

$$
\sigma^{2}\left(\overline{x_{i j}}\right)=\left(0.05 \bar{x}_{i j}\right)^{2}
$$

\subsection{Multi-criteria Optimization and Compromise Solution Method (VIKOR)}

The studies by Ju and Wang (2013, pp.3115-3116) and Tong, et al. (2007, pp. 1051-1052) were used for the mathematical form of the model. The basic approach of the VIKOR method is to identify positive and negative ideal points, and the VIKOR method is based on the idea of compromise.

$A 1, A 2, \ldots$ Am show various alternatives, and $C 1, C 2, \ldots$ Cn show all alternatives. For an alternative $A i$, fij is the value of the jth criterion $\mathrm{Cj}$. The compromise ranking algorithm is as follows. Here, the best $f^{*} j$ and the worst $f-j$ values of all criteria are determined, assuming that the criterion j represents a utility:

$$
\begin{aligned}
& f_{j}^{+}=\max _{1 \leq i \leq m} f_{i j}, j=1,2, \ldots, n, \\
& f_{j}^{-}=\min _{1 \leq i \leq m} f_{i j}, j=1,2, \ldots, n .
\end{aligned}
$$

The (Si) utility criterion and the (Ri) regret criterion are estimated using the equations (11) and (12):

$$
\begin{aligned}
& S_{i}=\sum_{j=1}^{n}\left[w_{j}\left(f_{j}^{+}-f_{i}^{j}\right) /\left(f_{j}^{+}-f_{j}^{-}\right)\right], i=1,2, \ldots, m, \\
& \left.R_{i}=\max _{1 \leq j \leq n}\left[w_{j}\left(f_{j}^{+}-f_{i j}\right) / f_{j}^{+}-f_{j}^{-}\right)\right], i=1,2, \ldots, m,
\end{aligned}
$$

where $w_{j}(j=1,2, \ldots, n)$

These are the criteria weights representing the decision maker's relative preference for the importance of the criteria. The values for ranking alternatives (Qi) are calculated using Equation 3,

$$
Q_{i}=v\left(S_{i}-S^{*}\right) /\left(S^{-}-S^{*}\right)+(1-v)\left(R_{i}-R^{*}\right) /\left(R^{-}-R^{*}\right), i=1,2, \ldots, m,
$$

Here, the letter $v$ is a weight reference and

$$
S^{*}=\min _{1 \leq i \leq m} S_{i},
$$




$$
\begin{aligned}
& S^{-}=\max _{1 \leq i \leq m} S_{i}, \\
& R^{*}=\min _{1 \leq i \leq m} R_{i}, \\
& R^{-}=\max _{1 \leq i \leq m} R_{i} .
\end{aligned}
$$

While $v$ is provided as the weight of the maximum group utilization strategy, (1-v) is the weight of individual regret. So, when $v$ is greater ( $v>0.5$ ), the Qi index tends to follow the rule of the majority.

Alternatives are ranked in ascending order according to the $S, R$, and $Q$ values. The results show three ranking lists.

If the following two conditions are met, a compromise solution can be proposed with the optimal alternative $(A(1))$ according to the (minimum) measure $\mathrm{Q}$. Thus,

$\mathrm{Con}_{1}=$ acceptable advantage:

$Q\left(A^{(2)}\right)-Q\left(A^{(1)}\right) \geq D Q$,

Here $(A(2))$, is the second-ranked alternative in the ranking list by $Q$,

$D Q=1 /(n-1)$

and $\mathrm{n}$ is the number of alternatives.

$\mathrm{Con}_{2}=$ acceptable stability in decision making:

Also, the alternative $(A(1))$ should be optimally ranked by $S$ and/or $R$.

This compromise solution is evaluated in a decision-making process, which can be the maximum group utilization strategy. Compromise is achieved as "majority vote" $v>0.5$ or "consensus" $v \approx 0.5$ or "veto" $v<0.5$. Here $v$ is the weight of the maximum group utility decision-making strategy.

If one of the conditions is not met, for example, when condition 2 is not met, a set of compromise solutions consisting of its alternatives or any other alternatives is recommended, such as: $(A(1)),(A(2)), \ldots,(A(M))$. The alternatives $(A(1))$ and $(A(2))$ are included in the compromised common solution. If condition 1 is not provided, all alternatives are included in the optimal solution set. The upper limit $\mathrm{M}$ is determined by the equation

$Q\left(A^{(M)}\right)-Q\left(A^{(1)}\right)<D Q$ The positions of the alternatives are close to each other.

\section{FINDINGS AND DISCUSSIONS ${ }^{1}$}

The solutions of the methods used in this section are included.

\subsection{WASPAS Solution}

In the first stage of the WASPAS method, the decision matrix was created. The decision matrix is shown in Appendix 1 and is an $86 \times 6$ matrix consisting of 86 alternatives and 6 criteria. In the second stage, the normalized decision matrix line (Xij) was obtained. For this reason, it was used by utilizing Equations 1 and 2. In the third stage, the WSM, a weighted average success criterion was calculated. Accordingly, Equation 3 was used. In the fourth stage, the total relative importance of the alternative was calculated according to the WPM method. Accordingly, Equation 4 was used. In the fifth stage, the common general criterion of the weighted

${ }^{1}$ There are ranked matrix operations on the basis of multi-criteria decision-making methods. The matrix used in the study is an $86 \times 6$ matrix. Since the matrices obtained from the application take up much space in the study, some of the matrices are included in the appendix section. Also, solution matrices are shortened in the solution section. 
aggregate of additive and multiplicative methods was calculated. For this purpose, Equation 5 was used. The QW values obtained showed the values to be used in the ranking of success. In the final stage, a more general equation could be used to determine the total relative importance of the alternative, Equation 6. However, the fact that the alternatives in the decision matrix used consisted of time series data made it unnecessary to use this equation. Weighted common general criteria and ranking values are presented in Table 1.

Table 1: Ranking Values Selected According to WASPAS Method (QW)

\begin{tabular}{|l|c|c|}
\hline City & QW & Rank \\
\hline Paris, France & 1.77 & 1 \\
\hline Antwerp, Belgium & 1.74 & 2 \\
\hline London, United Kingdom & 1.74 & 3 \\
\hline Brussels, Belgium & 1.69 & 4 \\
\hline Milan, Italy & 1.69 & 5 \\
\hline Rome, Italy & 1.65 & 6 \\
\hline $\begin{array}{l}\text { Manchester, United } \\
\text { Kingdom }\end{array}$ & 1.62 & 7 \\
\hline Zurich, Switzerland & 1.61 & 8 \\
\hline Bucharest, Romania & 1.61 & 9 \\
\hline Turin, Italy & 1.60 & 10 \\
\hline Geneva, Switzerland & 1.59 & 11 \\
\hline Barcelona, Spain & 1.57 & 12 \\
\hline Tirana, Albania & 1.57 & 13 \\
\hline Madrid, Spain & 1.57 & 14 \\
\hline Lyon, France & 1.57 & 15 \\
\hline
\end{tabular}

\subsubsection{WASPAS Lambda $(\lambda)$ Value}

The effect of the lambda $(\lambda)$ parameter on the ranking performance of the WASPAS method was examined. The determination of $(\lambda)$ values further increased the accuracy and effectiveness of this method in the decision-making process. The value $(\lambda)$ ranged from 0 to 1 . Accordingly, higher performance results were obtained at higher $(\lambda)$ values. In the study, $(\lambda)$ value was estimated by using the standard deviation and variance values of Q1, and Q2. $(\lambda)$ was found to be 0.71 .

$$
\lambda=\frac{0,13^{2}}{0,21^{2}+0,13^{2}}=0,71
$$

\subsection{VIKOR Solution}

In the first stage, the decision matrix is created. In the second stage, the normalized decision matrix is calculated. In the third stage, the weighted normalized decision matrix is calculated. In the fourth stage, Si and Ri values are calculated. For this purpose, Equations 11 and 12 are used. In the final stage, the QV ranking value is estimated. For this purpose, Equation 13 is used. The QV ranking values are displayed in Table 2 . 
Table 2: Ranking Values (QV) Selected According to VIKOR Method

\begin{tabular}{|l|c|c|l|c|c|}
\hline City & QV & Rank AZ & City & QV & Rank ZA \\
\hline Vienna, Austria & 0.03 & 1 & Tirana, Albania & 1.00 & 1 \\
\hline Helsinki, Finland & 0.06 & 2 & Kharkiv, Ukraine & 0.94 & 2 \\
\hline Munich, Germany & 0.09 & 3 & Dnipro, Ukraine & 0.92 & 3 \\
\hline Düsseldorf, Germany & 0.09 & 4 & Moscow, Russia & 0.90 & 4 \\
\hline Eindhoven, Netherlands & 0.09 & 5 & Odessa (Odesa), Ukraine & 0.89 & 5 \\
\hline Edinburgh, UK & 0.10 & 6 & Novosibirsk, Russia & 0.89 & 6 \\
\hline The Hague (Den Haag), Netherlands & 0.11 & 7 & Budapest, Hungary & 0.86 & 7 \\
\hline Valencia, Spain & 0.16 & 8 & Rome, Italy & 0.86 & 8 \\
\hline Rotterdam, Netherlands & 0.17 & 9 & Yekaterinburg, Russia & 0.85 & 9 \\
\hline Copenhagen, Denmark & 0.19 & 10 & Skopje, North Macedonia & 0.85 & 10 \\
\hline Utrecht, Netherlands & 0.20 & 11 & Kiev (Kiev), Ukraine & 0.84 & 11 \\
\hline Luxembourg, Luxembourg & 0.20 & 12 & Athens, Greece & 0.82 & 12 \\
\hline Cambridge, UK & 0.21 & 13 & Lodz, Poland & 0.82 & 13 \\
\hline Reykjavik, Iceland & 0.22 & 14 & Belgrade Serbia & 0.81 & 14 \\
\hline Tallinn, Estonia & 0.22 & 15 & Dublin, Ireland & 0.81 & 15 \\
\hline
\end{tabular}

\subsubsection{VIKOR Condition Tests}

For the accuracy of the obtained ranking, the requirements of Condition 1 and Condition 2 were examined. The results obtained with the VIKOR method were reliable because they were provided in both conditions. The respective calculations are as follows

Con $_{1}=$ acceptable advantage:

$D Q=\frac{1}{(86-1)}=0,01$

$Q\left(A^{(2)}\right)-Q\left(A^{(1)}\right) \geq D Q$

$0,06-0,03 \geq 0,01$

$\mathrm{Con}_{2}=$ acceptable stability in decision making:

Since it is ranked first in the Qi ranking with the smallest value and first in the Si and Ri rankings with the smallest value, it provides all the conditions.

\section{SENSITIVITY ANALYSIS}

The performance values estimated to carry out the sensitivity analysis were examined with the Spearman correlation approach. This relationship is presented in Table 3 where it may be seen that there is a strong positive relationship between the methods used and the values obtained. Accordingly, there is a positive relationship between WASPAS and VIKOR. This result demonstrates that the two methods can be used interchangeably. The same strong relationship is also valid for the life quality index. Accordingly, 
the life quality index calculations and WASPAS and VIKOR calculations provided remarkably similar results. The results were found to be statistically significant.

Table 3: Relationship Between Performance Values

\begin{tabular}{|l|l|l|l|l|l|}
\hline & & Correlations & & & \\
\hline & & & QW & QV & Index \\
\hline Spearman's rho & QW & Correlation Coefficient & 1.000 & $.999^{* *}$ & $.841^{* *}$ \\
\hline & & Sig. (2-tailed) &. & .000 & .000 \\
\hline & & N & 86 & 86 & 86 \\
\hline & QV & Correlation Coefficient & $.999 * *$ & 1.000 & $.842^{* *}$ \\
\hline & & Sig. (2-tailed) & .000 &. & .000 \\
\hline & & N & 86 & 86 & 86 \\
\hline & Index & Correlation Coefficient & $.841^{* *}$ & $.842 * *$ & 1.000 \\
\hline & & Sig. (2-tailed) & .000 & .000 &. \\
\hline (2-tailed). & & $\mathrm{N}$ & 86 & 86 & 86 \\
\hline
\end{tabular}

\section{CONCLUSION}

Multi-criteria decision-making (MCDM) forms the basis of modern decision science and operational research involving multiple decision alternatives. The purpose of MCDM is to find the most desired alternatives in a range of available alternatives based on the selected criteria. Generally, real-world problems are complex, and it is impossible to make the most appropriate decision considering only one criterion. Decision-making problems usually include four basic elements. These are alternatives that can be substituted for each other, assessment criteria, result matrices for alternatives, and the decision regarding the degree of importance of the criteria.

The weighted aggregated sum product assessment (WASPAS) method is a combination of the weighted sum model (WSM) and the weighted product model (WPM). It is widely accepted as an effective decision-making tool due to its mathematical simplicity and ability to provide more accurate results compared to the WSM and WPM methods. The VIKOR method focuses on ranking and selecting a number of alternatives and identifies compromise solutions to a problem. The compromise solution here is a viable solution closest to the ideal solution. Thus, the maximum group utility and the least individual regret is provided for decision makers in the VIKOR method.

As explained above, MCDM methods primarily aim to evaluate and rank available alternatives. However, there may be several situations where different MCDM methods provide distinct results. In other words, the rankings of the same alternatives may change depending on the methods adopted. This situation can be explained by the different mathematical calculations used in the considered methods.

When the findings were examined, there was a strong positive relationship between the methods used and the values obtained. Accordingly, there was a positive relationship between WASPAS and VIKOR. This result demonstrated that the two methods could be used interchangeably. The same strong relationship was also valid for the life quality index. Accordingly, the life quality index calculations, and WASPAS and VIKOR calculations provided remarkably similar results. The results were found to be statistically significant.

\section{REFERENCES}

Bazzazi, A. A., Osanloo, M., and Karimi, B. (2011). Deriving preference order of open pit mines equipment through MADM methods: Application of modified VIKOR method. Expert Systems with Applications, 38(3), 2550-2556. 
Chakraborty, S., and Zavadskas, E. K. (2014). Applications of WASPAS method in manufacturing decision making. Informatica, 25(1), 1-20.

Chakraborty, S., Zavadskas, E. K., and Antucheviciene, J. (2015). Applications of WASPAS Method as a Multi-Criteria Decision-Making Tool. Economic Computation and Economic Cybernetics Studies and Research, 49(1).

Datta, S., Mahapatra, S. S., Banerjee, S., and Bandyopadhyay, A. (2010). Comparative study on application of utility concept and VIKOR method for vendor selection.

Deveci, M., Canıtez, F., and Gökaşar, I. (2018). WASPAS and TOPSIS Based Interval Type-2 Fuzzy MCDM Method for a Selection of a Car-sharing Station. Sustainable Cities and Society, 41, 777-791.

Devi, K. (2011). Extension of VIKOR method in intuitionistic fuzzy environment for robot selection. Expert Systems with Applications, 38(11), 1416314168.

Ghorabaee, M. K., Zavadskas, E. K., Amiri, M., and Esmaeili, A. (2016). Multi-criteria evaluation of green suppliers using an extended WASPAS method with interval type-2 fuzzy sets. Journal of Cleaner Production, 137, 213-229.

Ju, Y., and Wang, A. (2013). Extension of VIKOR Method for Multi-Criteria Group Decision Making Problem with Linguistic İnformation. Applied Mathematical Modelling, 37(5), 3112-3125.

Karabašević, D., Stanujkić, D., Urošević, S., and Maksimović, M. (2016). An approach to personnel selection based on SWARA and WASPAS methods. Bizinfo (Blace) Journal of Economics, Management, and Informatics, 7(1), 1-11.

Keshavarz Ghorabaee, M., Amiri, M., Kazimieras Zavadskas, E., and Antuchevičienè, J. (2017). Assessment of third-party logistics providers using a CRITIC-WASPAS approach with interval type-2 fuzzy sets. Transport, 32(1), 66-78.

Liu, P., and Wu, X. (2012). A Competency Evaluation Method of Human Resources Managers Based on Multi-Granularity Linguistic Variables and VIKOR Method. Technological and Economic Development of Economy, 18(4), 696-710.

Madić, M., Gecevska, V., Radovanović, M., and Petković, D. (2014). Multi-criteria economic analysis of machining processes using the WASPAS method. Journal of Production Engineering, 17(2), 1-6.

Opricovic, S. (2016). A comparative analysis of the DEA-CCR model and the VIKOR method. Yugoslav Journal of Operations Research, 18(2).

Opricovic, S., and Tzeng, G. H. (2004). Compromise solution by MCDM methods: A comparative analysis of VIKOR and TOPSIS. European Journal of Operational Research, 156(2), 445-455.

Rezaie, K., Ramiyani, S. S., Nazari-Shirkouhi, S., and Badizadeh, A. (2014). Evaluating performance of Iranian cement firms using an integrated fuzzy AHP-VIKOR method. Applied Mathematical Modelling, 38(21-22), 5033-5046.

Stanujkić, D., and Karabašević, D. (2018). An extension of the WASPAS method for decision-making problems with intuitionistic fuzzy numbers: a case of website evaluation. Operational Research in Engineering Sciences: Theory and Applications, 1(1), 29-39.

Stojić, G., Stević, Ž., Antuchevičienė, J., Pamučar, D., and Vasiljević, M. (2018). A novel rough WASPAS approach for supplier selection in a company manufacturing PVC carpentry products. Information, 9(5), 121.

Tong, L. I., Chen, C. C., and Wang, C. H. (2007). Optimization of multi-response processes using the VIKOR method. The International Journal of Advanced Manufacturing Technology, 31(11-12), 1049-1057.

Urosevic, S., Karabasevic, D., Stanujkic, D., and Maksimovic, M. (2017). An Approach to Personnel Selection in the Tourism Industry Based on the SWARA and the WASPAS Methods. Economic Computation and Economic Cybernetics Studies and Research, 51(1).

Zavadskas, E. K., Antucheviciene, J., Hajiagha, S. H. R., and Hashemi, S. S. (2014). Extension of weighted aggregated sum product assessment with interval-valued intuitionistic fuzzy numbers (WASPAS-IVIF). Applied Soft Computing, 24, 1013-1021.

Zavadskas, E. K., Chakraborty, S., Bhattacharyya, O., and Antuchevciene, J. (2015b). Application of WASPAS method as an optimization tool in nontraditional machining processes. Information Technology and Control, 44(1), 77-88.

Zavadskas, E., Baušys, R., and Lazauskas, M. (2015a). Sustainable assessment of alternative sites for the construction of a waste incineration plant by applying WASPAS method with single-valued neutrosophic set. Sustainability, 7(12), 15923-15936.

Zhang, X., and Xing, X. (2017). Probabilistic linguistic VIKOR method to evaluate green supply chain initiatives. Sustainability, 9(7), 1231. 


\section{Appendix 1: Decision Matrix}

\begin{tabular}{|c|c|c|c|c|c|c|c|c|}
\hline Rank & City & $\begin{array}{l}\text { Quality of } \\
\text { Life Index }\end{array}$ & $\begin{array}{l}\text { Purchasing } \\
\text { Power Index }\end{array}$ & $\begin{array}{l}\text { Safety } \\
\text { Index }\end{array}$ & $\begin{array}{l}\text { Health } \\
\text { Care Index }\end{array}$ & $\begin{array}{l}\text { Cost of } \\
\text { Living } \\
\text { Index } \\
\end{array}$ & $\begin{array}{l}\text { Traffic Commute } \\
\text { Time Index }\end{array}$ & $\begin{array}{l}\text { Pollution } \\
\text { Index } \\
\end{array}$ \\
\hline 1 & $\begin{array}{l}\text { Zurich, } \\
\text { Switzerland } \\
\end{array}$ & 197.90 & 123.04 & 83.16 & 73.69 & 126.87 & 33.72 & 17.77 \\
\hline 2 & $\begin{array}{l}\text { Eindhoven, } \\
\text { Netherlands }\end{array}$ & 191.09 & 92.82 & 74.64 & 73.04 & 73.02 & 25.76 & 22.24 \\
\hline 3 & $\begin{array}{l}\text { The Hague (Den } \\
\text { Haag), } \\
\text { Netherlands }\end{array}$ & 190.25 & 93.36 & 74.01 & 76.99 & 70.02 & 32.97 & 23.28 \\
\hline 4 & $\begin{array}{l}\text { Copenhagen, } \\
\text { Denmark } \\
\end{array}$ & 187.79 & 90.41 & 74.95 & 78.64 & 83.95 & 28.52 & 20.89 \\
\hline 5 & Vienna, Austria & 184.55 & 83.75 & 76.10 & 78.85 & 64.64 & 26.85 & 18.38 \\
\hline 6 & Reykjavik, Iceland & 183.00 & 75.49 & 77.74 & 66.70 & 85.28 & 20.17 & 15.52 \\
\hline 7 & $\begin{array}{l}\text { Luxembourg, } \\
\text { Luxembourg }\end{array}$ & 182.95 & 102.68 & 71.85 & 73.71 & 81.29 & 33.24 & 22.22 \\
\hline 8 & Helsinki, Finland & 182.42 & 88.85 & 77.24 & 77.60 & 71.80 & 31.63 & 12.78 \\
\hline 9 & Edinburgh, UK & 179.99 & 82.93 & 68.53 & 81.32 & 67.21 & 29.32 & 26.31 \\
\hline 10 & $\begin{array}{l}\text { Geneva, } \\
\text { Switzerland } \\
\end{array}$ & 179.52 & 108.89 & 71.41 & 68.89 & 121.85 & 25.88 & 29.26 \\
\hline 11 & Belfast, UK & 177.73 & 93.41 & 59.20 & 71.08 & 59.44 & 38.13 & 27.61 \\
\hline 12 & $\begin{array}{l}\text { Düsseldorf, } \\
\text { Germany }\end{array}$ & 177.41 & 96.71 & 69.02 & 72.21 & 65.20 & 30.31 & 31.28 \\
\hline 13 & $\begin{array}{l}\text { Munich, } \\
\text { Germany }\end{array}$ & 176.68 & 90.68 & 82.56 & 78.37 & 71.85 & 33.22 & 24.77 \\
\hline 14 & Valencia, Spain & 175.32 & 74.93 & 74.50 & 81.71 & 51.30 & 28.00 & 44.14 \\
\hline 15 & \begin{tabular}{|l} 
Utrecht, \\
Netherlands \\
\end{tabular} & 174.95 & 80.36 & 71.82 & 74.00 & 76.02 & 31.00 & 30.01 \\
\hline 16 & Glasgow, UK & 172.91 & 94.17 & 56.12 & 80.56 & 62.92 & 33.12 & 35.07 \\
\hline 17 & Tallinn, Estonia & 172.91 & 66.65 & 77.45 & 71.11 & 52.07 & 26.68 & 21.91 \\
\hline 18 & $\begin{array}{l}\text { Frankfurt, } \\
\text { Germany }\end{array}$ & 172.82 & 100.20 & 58.24 & 74.51 & 68.30 & 25.11 & 37.59 \\
\hline 19 & Cambridge, UK & 172.37 & 75.93 & 78.10 & 73.79 & 70.04 & 33.56 & 32.56 \\
\hline 20 & $\begin{array}{l}\text { Rotterdam, } \\
\text { Netherlands } \\
\end{array}$ & 171.55 & 84.26 & 65.33 & 76.36 & 69.13 & 28.19 & 40.17 \\
\hline 21 & $\begin{array}{l}\text { Gothenburg, } \\
\text { Sweden }\end{array}$ & 170.53 & 85.14 & 53.86 & 68.57 & 68.23 & 26.24 & 20.03 \\
\hline 22 & $\begin{array}{l}\text { Amsterdam, } \\
\text { Netherlands }\end{array}$ & 169.89 & 83.94 & 67.34 & 69.63 & 78.32 & 29.75 & 31.13 \\
\hline 23 & $\begin{array}{l}\text { Stuttgart, } \\
\text { Germany }\end{array}$ & 169.89 & 100.60 & 72.01 & 71.06 & 65.97 & 34.95 & 41.56 \\
\hline
\end{tabular}




\begin{tabular}{|c|c|c|c|c|c|c|c|c|}
\hline 24 & Leeds, UK & 169.89 & 97.77 & 58.34 & 82.58 & 60.69 & 31.95 & 46.86 \\
\hline 25 & Cork, Ireland & 169.18 & 74.27 & 65.37 & 57.68 & 75.30 & 34.30 & 23.20 \\
\hline 26 & $\begin{array}{l}\text { Hamburg, } \\
\text { Germany }\end{array}$ & 167.58 & 92.11 & 56.04 & 75.11 & 68.61 & 34.74 & 30.13 \\
\hline 27 & Berlin, Germany & 166.86 & 101.89 & 58.98 & 69.99 & 62.93 & 34.18 & 39.55 \\
\hline 28 & \begin{tabular}{|l} 
Ljubljana, \\
Slovenia \\
\end{tabular} & 166.47 & 59.65 & 78.68 & 66.24 & 54.98 & 27.84 & 23.24 \\
\hline 29 & Vilnius, Lithuania & 165.39 & 60.91 & 72.09 & 71.09 & 43.52 & 27.76 & 23.75 \\
\hline 30 & Bristol, UK & 164.80 & 87.10 & 62.10 & 73.54 & 69.11 & 28.59 & 44.05 \\
\hline 31 & Oslo, Norway & 162.86 & 85.77 & 63.37 & 75.07 & 86.38 & 32.23 & 25.88 \\
\hline 32 & Kaunas, Lithuania & 160.59 & 55.29 & 60.93 & 73.15 & 43.46 & 23.58 & 26.89 \\
\hline 33 & $\begin{array}{l}\text { Cologne, } \\
\text { Germany }\end{array}$ & 159.61 & 93.18 & 57.37 & 73.94 & 65.22 & 37.72 & 42.59 \\
\hline 34 & \begin{tabular}{|l} 
Stockholm, \\
Sweden
\end{tabular} & 159.09 & 84.64 & 55.54 & 67.05 & 74.37 & 36.49 & 18.94 \\
\hline 35 & Zagreb, Croatia & 159.02 & 52.63 & 78.04 & 65.63 & 48.80 & 31.43 & 31.18 \\
\hline 36 & \begin{tabular}{|l} 
Brno, Czech \\
Republic
\end{tabular} & 158.88 & 63.14 & 73.32 & 74.26 & 42.11 & 26.14 & 44.35 \\
\hline 37 & $\begin{array}{l}\text { Prague, Czech } \\
\text { Republic } \\
\end{array}$ & 157.48 & 62.67 & 75.79 & 74.20 & 44.71 & 32.41 & 35.11 \\
\hline 38 & Lyon, France & 157.07 & 82.93 & 56.79 & 77.00 & 72.09 & 33.90 & 47.35 \\
\hline 39 & $\begin{array}{l}\text { Timisoara, } \\
\text { Romania } \\
\end{array}$ & 155.77 & 59.25 & 76.36 & 71.42 & 34.07 & 23.88 & 56.42 \\
\hline 40 & Porto, Portugal & 155.22 & 43.51 & 63.41 & 74.62 & 48.49 & 28.72 & 36.02 \\
\hline 41 & $\begin{array}{l}\text { Antwerp, } \\
\text { Belgium }\end{array}$ & 154.63 & 84.20 & 65.22 & 80.53 & 70.31 & 37.15 & 61.23 \\
\hline 42 & Madrid, Spain & 152.14 & 68.92 & 70.08 & 79.28 & 58.57 & 35.23 & 51.79 \\
\hline 43 & Lisbon, Portugal & 151.99 & 46.61 & 72.10 & 71.49 & 49.34 & 36.28 & 34.85 \\
\hline 44 & $\begin{array}{l}\text { Cluj-Napoca, } \\
\text { Romania } \\
\end{array}$ & 150.67 & 51.03 & 79.49 & 64.17 & 35.94 & 28.91 & 43.40 \\
\hline 45 & \begin{tabular}{|l} 
Birmingham, \\
United Kingdom
\end{tabular} & 150.24 & 80.27 & 42.19 & 73.75 & 66.89 & 32.17 & 47.87 \\
\hline 46 & $\begin{array}{l}\text { Manchester, } \\
\text { United Kingdom }\end{array}$ & 148.05 & 89.64 & 44.97 & 78.16 & 65.83 & 40.10 & 53.40 \\
\hline 47 & $\begin{array}{l}\text { Bratislava, } \\
\text { Slovakia } \\
\end{array}$ & 147.39 & 61.40 & 68.63 & 57.17 & 47.55 & 30.89 & 41.12 \\
\hline 48 & Brussels, Belgium & 144.24 & 89.32 & 48.73 & 74.18 & 69.75 & 37.17 & 62.30 \\
\hline 49 & Riga, Latvia & 143.77 & 50.65 & 61.46 & 60.68 & 48.24 & 32.48 & 38.65 \\
\hline 50 & $\begin{array}{l}\text { Nizhny Novgorod, } \\
\text { Russia }\end{array}$ & 143.43 & 35.93 & 69.57 & 76.82 & 32.55 & 29.10 & 34.03 \\
\hline 51 & Bologna, Italy & 141.64 & 59.02 & 55.14 & 77.88 & 68.41 & 32.04 & 55.73 \\
\hline
\end{tabular}




\begin{tabular}{|c|c|c|c|c|c|c|c|c|}
\hline 52 & Barcelona, Spain & 138.54 & 63.13 & 55.35 & 77.67 & 57.48 & 30.22 & 64.91 \\
\hline 53 & Dublin, Ireland & 137.56 & 69.79 & 50.27 & 51.53 & 77.45 & 40.51 & 40.55 \\
\hline 54 & Varna, Bulgaria & 137.09 & 46.10 & 68.24 & 62.58 & 36.44 & 31.46 & 61.37 \\
\hline 55 & Novi Sad, Serbia & 136.49 & 42.48 & 59.66 & 47.35 & 34.46 & 17.17 & 45.88 \\
\hline 56 & Minsk, Belarus & 135.66 & 33.75 & 75.48 & 62.59 & 34.55 & 30.35 & 41.56 \\
\hline 57 & $\begin{array}{l}\text { London, United } \\
\text { Kingdom } \\
\end{array}$ & 131.29 & 87.10 & 47.45 & 69.97 & 77.67 & 45.17 & 58.50 \\
\hline 58 & Age, Romania & 128.94 & 46.23 & 71.98 & 56.75 & 34.92 & 34.62 & 61.50 \\
\hline 59 & Turin, Italy & 127.77 & 62.44 & 48.06 & 69.52 & 65.36 & 29.62 & 70.02 \\
\hline 60 & Warsaw, Poland & 125.49 & 55.58 & 71.73 & 55.75 & 40.59 & 35.94 & 64.22 \\
\hline 61 & Sofia, Bulgaria & 123.72 & 53.15 & 57.75 & 57.17 & 38.94 & 30.96 & 69.14 \\
\hline 62 & $\begin{array}{l}\text { Thessaloniki, } \\
\text { Greece }\end{array}$ & 123.46 & 37.33 & 59.71 & 56.19 & 56.17 & 26.94 & 64.10 \\
\hline 63 & Gdansk, Poland & 122.93 & 51.48 & 64.19 & 48.20 & 38.72 & 30.93 & 59.59 \\
\hline 64 & Wroclaw, Poland & 121.94 & 52.04 & 67.53 & 51.89 & 37.72 & 33.63 & 67.79 \\
\hline 65 & Poznan, Poland & 121.06 & 46.91 & 69.56 & 51.08 & 37.03 & 30.97 & 66.32 \\
\hline 66 & Athens, Greece & 120.39 & 41.49 & 50.87 & 55.94 & 56.14 & 37.98 & 57.33 \\
\hline 67 & $\begin{array}{l}\text { Budapest, } \\
\text { Hungary }\end{array}$ & 119.76 & 48.54 & 63.74 & 47.23 & 41.20 & 39.14 & 54.70 \\
\hline 68 & Milan, Italy & 119.46 & 54.32 & 56.86 & 71.80 & 75.63 & 37.13 & 66.19 \\
\hline 69 & Lviv, Ukraine & 119.45 & 31.02 & 57.65 & 58.94 & 29.92 & 33.05 & 54.57 \\
\hline 70 & $\begin{array}{l}\text { Bucharest, } \\
\text { Romania } \\
\end{array}$ & 118.93 & 52.97 & 72.67 & 54.31 & 38.17 & 42.17 & 75.39 \\
\hline 71 & Cracow, Poland & 117.45 & 54.96 & 68.56 & 52.48 & 38.58 & 30.97 & 76.05 \\
\hline 72 & Paris, France & 116.13 & 66.03 & 47.98 & 78.46 & 85.06 & 42.38 & 64.28 \\
\hline 73 & Lodz, Poland & 113.34 & 49.00 & 54.29 & 50.44 & 36.41 & 31.70 & 73.96 \\
\hline 74 & Rome, Italy & 112.24 & 56.15 & 47.94 & 58.90 & 69.46 & 42.77 & 66.66 \\
\hline 75 & $\begin{array}{l}\text { Sarajevo, Bosnia } \\
\text { and Herzegovina }\end{array}$ & 110.75 & 42.07 & 51.10 & 53.87 & 37.99 & 28.84 & 71.18 \\
\hline 76 & Belgrade Serbia & 109.16 & 35.43 & 62.47 & 53.88 & 38.09 & 35.85 & 63.45 \\
\hline 77 & Kharkiv, Ukraine & 108.93 & 31.24 & 51.84 & 46.61 & 30.10 & 37.82 & 55.77 \\
\hline 78 & $\begin{array}{l}\text { Odessa (Odesa), } \\
\text { Ukraine }\end{array}$ & 108.86 & 34.00 & 47.24 & 51.57 & 31.22 & 35.78 & 64.25 \\
\hline 79 & $\begin{array}{l}\text { Kiev (Kiev), } \\
\text { Ukraine }\end{array}$ & 106.77 & 39.34 & 52.89 & 55.55 & 32.82 & 43.11 & 66.05 \\
\hline 80 & $\begin{array}{l}\text { Saint Petersburg, } \\
\text { Russia }\end{array}$ & 106.39 & 42.09 & 60.92 & 58.91 & 35.64 & 47.53 & 62.51 \\
\hline 81 & $\begin{array}{l}\text { Skopje, North } \\
\text { Macedonia }\end{array}$ & 103.35 & 34.87 & 56.04 & 55.93 & 34.81 & 28.60 & 82.90 \\
\hline
\end{tabular}




\begin{tabular}{|l|l|l|l|l|l|l|l|l|}
82 & Moscow, Russia & 102.93 & 49.62 & 60.04 & 61.35 & 40.04 & 52.40 & 59.41 \\
\hline 83 & Dnipro, Ukraine & 96.62 & 33.58 & 47.11 & 51.29 & 29.99 & 32.21 & 82.36 \\
\hline 84 & Tirana, Albania & 90.31 & 27.96 & 61.08 & 49.28 & 37.38 & 41.58 & 87.21 \\
\hline 85 & $\begin{array}{l}\text { Yekaterinburg, } \\
\text { Russia }\end{array}$ & 87.08 & 44.02 & 52.75 & 50.78 & 30.96 & 38.49 & 76.86 \\
\hline 86 & $\begin{array}{l}\text { Novosibirsk, } \\
\text { Russia }\end{array}$ & 85.50 & 34.57 & 51.94 & 53.35 & 30.64 & 40.10 & 68.98 \\
\hline
\end{tabular}

Appendix 2: WASPAS

\begin{tabular}{|l|l|l|}
\hline City & QW & Rank \\
\hline Paris, France & 1.77 & 1 \\
\hline Antwerp, Belgium & 1.74 & 2 \\
\hline London, United Kingdom & 1.74 & 3 \\
\hline Brussels, Belgium & 1.69 & 4 \\
\hline Milan, Italy & 1.69 & 5 \\
\hline Rome, Italy & 1.65 & 6 \\
\hline Manchester, United Kingdom & 1.62 & 7 \\
\hline Zurich, Switzerland & 1.61 & 8 \\
\hline Bucharest, Romania & 1.61 & 9 \\
\hline Turin, Italy & 1.60 & 10 \\
\hline Geneva, Switzerland & 1.59 & 11 \\
\hline Barcelona, Spain & 1.57 & 12 \\
\hline Tirana, Albania & 1.57 & 13 \\
\hline Madrid, Spain & 1.57 & 14 \\
\hline Lyon, France & 1.57 & 15 \\
\hline Stuttgart, Germany & 1.56 & 16 \\
\hline Bologna, Italy & 1.55 & 17 \\
\hline Moscow, Russia & 1.54 & 18 \\
\hline Leeds, UK & 1.54 & 19 \\
\hline Cologne, Germany & 1.54 & 20 \\
\hline Cracow, Poland & 1.52 & 21 \\
\hline Warsaw, Poland & 1.50 & 22 \\
\hline Bristol, UK & 1.49 & 23 \\
\hline Saint Petersburg, Russia & 278 & 24 \\
\hline Berlin, Germany & 25 \\
\hline Birmingham, United Kingdom & 1.48 \\
\hline Yekaterinburg, Russia & 27 \\
\hline
\end{tabular}




\begin{tabular}{|c|c|c|}
\hline Rotterdam, Netherlands & 1.46 & 28 \\
\hline Wroclaw, Poland & 1.46 & 29 \\
\hline Dublin, Ireland & 1.46 & 30 \\
\hline Skopje, North Macedonia & 1.45 & 31 \\
\hline Cambridge, UK & 1.45 & 32 \\
\hline Sofia, Bulgaria & 1.45 & 33 \\
\hline Lodz, Poland & 1.44 & 34 \\
\hline Athens, Greece & 1.44 & 35 \\
\hline Valencia, Spain & 1.43 & 36 \\
\hline Glasgow, UK & 1.43 & 37 \\
\hline Kiev (Kiev), Ukraine & 1.43 & 38 \\
\hline Munich, Germany & 1.42 & 39 \\
\hline Oslo, Norway & 1.42 & 40 \\
\hline Utrecht, Netherlands & 1.42 & 41 \\
\hline Luxembourg, Luxembourg & 1.42 & 42 \\
\hline Amsterdam, Netherlands & 1.42 & 43 \\
\hline Thessaloniki, Greece & 1.42 & 44 \\
\hline Frankfurt, Germany & 1.41 & 45 \\
\hline Poznan, Poland & 1.41 & 46 \\
\hline Dnipro, Ukraine & 1.41 & 47 \\
\hline Age, Romania & 1.41 & 48 \\
\hline Hamburg, Germany & 1.40 & 49 \\
\hline Düsseldorf, Germany & 1.40 & 50 \\
\hline Varna, Bulgaria & 1.40 & 51 \\
\hline Novosibirsk, Russia & 1.39 & 52 \\
\hline Belgrade, Serbia & 1.39 & 53 \\
\hline Sarajevo, Bosnia and Herzegovina & 1.39 & 54 \\
\hline Budapest, Hungary & 1.38 & 55 \\
\hline The Hague (Den Haag), Netherlands & 1.38 & 56 \\
\hline Copenhagen, Denmark & 1.37 & 57 \\
\hline Belfast, UK & 1.37 & 58 \\
\hline Gdansk, Poland & 1.36 & 59 \\
\hline Timisoara, Romania & 1.36 & 60 \\
\hline Edinburgh, UK & 1.35 & 61 \\
\hline Brno, Czech Republic & 1.33 & 62 \\
\hline Prague, Czech Republic & 1.31 & 63 \\
\hline
\end{tabular}




\begin{tabular}{|c|c|c|}
\hline Eindhoven, Netherlands & 1.31 & 64 \\
\hline Odessa (Odesa), Ukraine & 1.31 & 65 \\
\hline Lisbon, Portugal & 1.31 & 66 \\
\hline Bratislava, Slovakia & 1.31 & 67 \\
\hline Cork, Ireland & 1.30 & 68 \\
\hline Stockholm, Sweden & 1.29 & 69 \\
\hline Cluj-Napoca, Romania & 1.27 & 70 \\
\hline Riga, Latvia & 1.27 & 71 \\
\hline Zagreb, Croatia & 1.25 & 72 \\
\hline Helsinki, Finland & 1.25 & 73 \\
\hline Lviv, Ukraine & 1.24 & 74 \\
\hline Vienna, Austria & 1.24 & 75 \\
\hline Kharkiv, Ukraine & 1.24 & 76 \\
\hline Porto, Portugal & 1.23 & 77 \\
\hline Minsk, Belarus & 1.20 & 78 \\
\hline Gothenburg, Sweden & 1.19 & 79 \\
\hline Reykjavik, Iceland & 1.19 & 80 \\
\hline Ljubljana, Slovenia & 1.19 & 81 \\
\hline Tallinn, Estonia & 1.17 & 82 \\
\hline Vilnius, Lithuania & 1.14 & 83 \\
\hline Nizhny Novgorod, Russia & 1.13 & 84 \\
\hline Kaunas, Lithuania & 1.10 & 85 \\
\hline Novi Sad, Serbia & 1.07 & 86 \\
\hline
\end{tabular}

\section{Appendix 3: VIKOR}

\begin{tabular}{|l|l|l|l|l|l|}
\hline City & QV & Rank & City & QV & Rank \\
\hline Vienna, Austria & 0.03 & 1 & Tirana, Albania & 1.00 & 1 \\
\hline Helsinki, Finland & 0.06 & 2 & Kharkiv, Ukraine & 0.94 & 2 \\
\hline Munich, Germany & 0.09 & 3 & Dnipro, Ukraine & 0.92 & 3 \\
\hline Düsseldorf, Germany & 0.09 & 4 & Moscow, Russia & 0.90 & 4 \\
\hline Eindhoven, Netherlands & 0.09 & 5 & Odessa (Odesa), Ukraine & 0.89 & 5 \\
\hline Edinburgh, UK & 0.10 & 6 & Novosibirsk, Russia & 0.89 & 6 \\
\hline The Hague (Den Haag), Netherlands & 0.11 & 7 & Budapest, Hungary & 0.86 & 7 \\
\hline Valencia, Spain & 0.16 & 8 & Rome, Italy & 0.86 & 8 \\
\hline Rotterdam, Netherlands & 0.17 & 9 & Yekaterinburg, Russia & 0.85 & 9 \\
\hline
\end{tabular}




\begin{tabular}{|c|c|c|c|c|c|}
\hline Copenhagen, Denmark & 0.19 & 10 & Skopje, North Macedonia & 0.85 & 10 \\
\hline Utrecht, Netherlands & 0.20 & 11 & Kiev (Kiev), Ukraine & 0.84 & 11 \\
\hline Luxembourg, Luxembourg & 0.20 & 12 & Athens, Greece & 0.82 & 12 \\
\hline Cambridge, UK & 0.21 & 13 & Lodz, Poland & 0.82 & 13 \\
\hline Reykjavik, Iceland & 0.22 & 14 & Belgrade Serbia & 0.81 & 14 \\
\hline Tallinn, Estonia & 0.22 & 15 & Dublin, Ireland & 0.81 & 15 \\
\hline Stuttgart, Germany & 0.23 & 16 & Lviv, Ukraine & 0.80 & 16 \\
\hline Amsterdam, Netherlands & 0.25 & 17 & Gdansk, Poland & 0.80 & 17 \\
\hline Bristol, UK & 0.27 & 18 & Saint Petersburg, Russia & 0.79 & 18 \\
\hline Brno, Czech Republic & 0.29 & 19 & Thessaloniki, Greece & 0.78 & 19 \\
\hline Frankfurt, Germany & 0.30 & 20 & Birmingham, United Kingdom & 0.78 & 20 \\
\hline Vilnius, Lithuania & 0.30 & 21 & Sarajevo, Bosnia and Herzegovina & 0.78 & 21 \\
\hline Prague, Czech Republic & 0.30 & 22 & London, United Kingdom & 0.77 & 22 \\
\hline Leeds, UK & 0.30 & 23 & Paris, France & 0.77 & 23 \\
\hline Madrid, Spain & 0.32 & 24 & Novi Sad, Serbia & 0.75 & 24 \\
\hline Oslo, Norway & 0.32 & 25 & Turin, Italy & 0.73 & 25 \\
\hline Ljubljana, Slovenia & 0.33 & 26 & Bucharest, Romania & 0.73 & 26 \\
\hline Timisoara, Romania & 0.34 & 27 & Manchester, United Kingdom & 0.72 & 27 \\
\hline Belfast, UK & 0.34 & 28 & Poznan, Poland & 0.72 & 28 \\
\hline Berlin, Germany & 0.34 & 29 & Wroclaw, Poland & 0.71 & 29 \\
\hline Glasgow, UK & 0.35 & 30 & Cracow, Poland & 0.71 & 30 \\
\hline Kaunas, Lithuania & 0.38 & 31 & Brussels, Belgium & 0.67 & 31 \\
\hline Hamburg, Germany & 0.39 & 32 & Minsk, Belarus & 0.64 & 32 \\
\hline Cologne, Germany & 0.40 & 33 & Sofia, Bulgaria & 0.64 & 33 \\
\hline Antwerp, Belgium & 0.42 & 34 & Milan, Italy & 0.64 & 34 \\
\hline Gothenburg, Sweden & 0.42 & 35 & Age, Romania & 0.63 & 35 \\
\hline Lyon, France & 0.43 & 36 & Geneva, Switzerland & 0.61 & 36 \\
\hline Zagreb, Croatia & 0.43 & 37 & Varna, Bulgaria & 0.60 & 37 \\
\hline Cluj-Napoca, Romania & 0.44 & 38 & Warsaw, Poland & 0.59 & 38 \\
\hline Stockholm, Sweden & 0.45 & 39 & Riga, Latvia & 0.57 & 39 \\
\hline Bratislava, Slovakia & 0.49 & 40 & Zurich, Switzerland & 0.57 & 40 \\
\hline Cork, Ireland & 0.49 & 41 & Nizhny Novgorod, Russia & 0.55 & 41 \\
\hline Barcelona, Spain & 0.51 & 42 & Porto, Portugal & 0.54 & 42 \\
\hline Bologna, Italy & 0.51 & 43 & Lisbon, Portugal & 0.52 & 43 \\
\hline Lisbon, Portugal & 0.52 & 44 & Bologna, Italy & 0.51 & 44 \\
\hline Porto, Portugal & 0.54 & 45 & Barcelona, Spain & 0.51 & 45 \\
\hline
\end{tabular}




\begin{tabular}{|c|c|c|c|c|c|}
\hline Nizhny Novgorod, Russia & 0.55 & 46 & Cork, Ireland & 0.49 & 46 \\
\hline Zurich, Switzerland & 0.57 & 47 & Bratislava, Slovakia & 0.49 & 47 \\
\hline Riga, Latvia & 0.57 & 48 & Stockholm, Sweden & 0.45 & 48 \\
\hline Warsaw, Poland & 0.59 & 49 & Cluj-Napoca, Romania & 0.44 & 49 \\
\hline Varna, Bulgaria & 0.60 & 50 & Zagreb, Croatia & 0.43 & 50 \\
\hline Geneva, Switzerland & 0.61 & 51 & Lyon, France & 0.43 & 51 \\
\hline Age, Romania & 0.63 & 52 & Gothenburg, Sweden & 0.42 & 52 \\
\hline Milan, Italy & 0.64 & 53 & Antwerp, Belgium & 0.42 & 53 \\
\hline Sofia, Bulgaria & 0.64 & 54 & Cologne, Germany & 0.40 & 54 \\
\hline Minsk, Belarus & 0.64 & 55 & Hamburg, Germany & 0.39 & 55 \\
\hline Brussels, Belgium & 0.67 & 56 & Kaunas, Lithuania & 0.38 & 56 \\
\hline Cracow, Poland & 0.71 & 57 & Glasgow, UK & 0.35 & 57 \\
\hline Wroclaw, Poland & 0.71 & 58 & Berlin, Germany & 0.34 & 58 \\
\hline Poznan, Poland & 0.72 & 59 & Belfast, UK & 0.34 & 59 \\
\hline Manchester, United Kingdom & 0.72 & 60 & Timisoara, Romania & 0.34 & 60 \\
\hline Bucharest, Romania & 0.73 & 61 & Ljubljana, Slovenia & 0.33 & 61 \\
\hline Turin, Italy & 0.73 & 62 & Oslo, Norway & 0.32 & 62 \\
\hline Novi Sad, Serbia & 0.75 & 63 & Madrid, Spain & 0.32 & 63 \\
\hline Paris, France & 0.77 & 64 & Leeds, UK & 0.30 & 64 \\
\hline London, United Kingdom & 0.77 & 65 & Prague, Czech Republic & 0.30 & 65 \\
\hline Sarajevo, Bosnia and Herzegovina & 0.78 & 66 & Vilnius, Lithuania & 0.30 & 66 \\
\hline Birmingham, United Kingdom & 0.78 & 67 & Frankfurt, Germany & 0.30 & 67 \\
\hline Thessaloniki, Greece & 0.78 & 68 & Brno, Czech Republic & 0.29 & 68 \\
\hline Saint Petersburg, Russia & 0.79 & 69 & Bristol, UK & 0.27 & 69 \\
\hline Gdansk, Poland & 0.80 & 70 & Amsterdam, Netherlands & 0.25 & 70 \\
\hline Lviv, Ukraine & 0.80 & 71 & Stuttgart, Germany & 0.23 & 71 \\
\hline Dublin, Ireland & 0.81 & 72 & Tallinn, Estonia & 0,22 & 72 \\
\hline Belgrade Serbia & 0.81 & 73 & Reykjavik, Iceland & 0,22 & 73 \\
\hline Lodz, Poland & 0.82 & 74 & Cambridge, UK & 0,21 & 74 \\
\hline Athens, Greece & 0.82 & 75 & Luxembourg, Luxembourg & 0,20 & 75 \\
\hline Kiev (Kiev), Ukraine & 0.84 & 76 & Utrecht, Netherlands & 0,20 & 76 \\
\hline Skopje, North Macedonia & 0.85 & 77 & Copenhagen, Denmark & 0,19 & 77 \\
\hline Yekaterinburg, Russia & 0.85 & 78 & Rotterdam, Netherlands & 0,17 & 78 \\
\hline Rome, Italy & 0.86 & 79 & Valencia, Spain & 0,16 & 79 \\
\hline Budapest, Hungary & 0.86 & 80 & The Hague (Den Haag), Netherlands & 0,11 & 80 \\
\hline Novosibirsk, Russia & 0.89 & 81 & Edinburgh, UK & 0,10 & 81 \\
\hline
\end{tabular}




\begin{tabular}{|l|l|l|l|l|l|} 
Odessa (Odesa), Ukraine & 0.89 & 82 & Eindhoven, Netherlands & 0,09 & 82 \\
\hline Moscow, Russia & 0.90 & 83 & Düsseldorf, Germany & 0,09 & 83 \\
\hline Dnipro, Ukraine & 0.92 & 84 & Munich, Germany & 0,09 & 84 \\
\hline Kharkiv, Ukraine & 0.94 & 85 & Helsinki, Finland & 0,06 & 85 \\
\hline Tirana, Albania & 1.00 & 86 & Vienna, Austria & 0,03 & 86 \\
\hline
\end{tabular}

